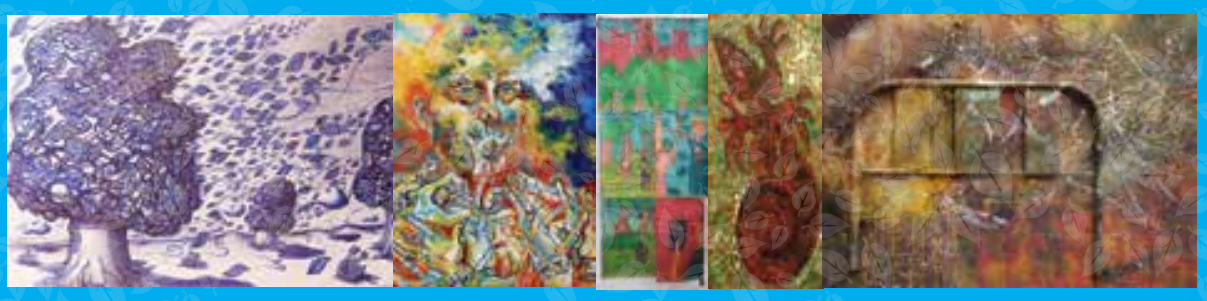

\title{
UNA PUBLICACIÓN CIENTÍFICA QUE SUPERA LO CIENTÍFICO
}

L

a Revista Colombiana de Rehabilitación, editada por la Fundación Escuela Colombiana de Rehabilitación - ECR- ha tenido una evolución muy interesante desde sus inicios hasta la edición de los volúmenes más recientes. Su madurez actual se puede analizar desde

tres miradas complementarias. La primera mirada hace relación a la calidad conceptual de los artículos que se incluyen en cada volumen; la segunda, hace relación a la estructura metodológica de las investigaciones de las cuales se desarrollan los artículos como producto derivado; y en tercer lugar la diagramación, como medio de entrada visual que invita al lector a deleitarse de conocimiento en un ambiente sensorialmente agradable.

En el primer componente relacionado con la conceptualización, la publicación ha evidenciado una apuesta por entregar a la comunidad académica y demás lectores de la revista, artículos más rigurosos en los abordajes de la información conceptual y teórica, resultado que se ha logrado, vinculando como medio esencial, a evaluadores con una importante experticia en los temas de los artículos postulados para arbitraje. Esto necesariamente se traduce en una publicación que aporta a la construcción de conocimiento vigente y actual; y puede ser contemplada como punto de referencia para la toma de decisiones profesionales alrededor de los resultados de investigación, o práctica profesional presentados.

Desde la estructura metodológica, la publicación ha sido firme en la convicción de que la información conceptual y teórica de calidad, requiere un cuerpo sólido sobre el cual sustentarse. Esto se logra a partir de la consistencia entre las problemáticas propuestas o reconocidas, con los métodos o diseños para resolverlas. En este punto, la revista realiza un arbitraje cuidadoso alrededor de la coherencia entre los alcances de la investigación, las rutas metodológicas, y por supuesto, los tipos y formas de análisis realizados, de modo que sean consecuentes con las intenciones de investigación y con la estructura de resultados propuesta, logrando así que las investigaciones publicadas puedan ser reconocidas para procesos de práctica basada en la evidencia científica.

La estructura metodológica para la Revista Colombiana de Rehabilitación, se constituye así en un componente clave que necesariamente habla de la calidad de los productos entregados en cada volumen; el equipo editorial reconoce que en rehabilitación es tan importante el contenido de los documentos como las miradas y posturas epistemológicas desde donde se construye la metodología, puesto que las problemáticas en salud que son presentadas en esta revista, requieren frecuentemente miradas tanto analíticas-cuantitativas así como interpretativas y críticas- cualitativas que van más allá de lo nominal, que requieren claridad de los investigadores en los abordajes a realizar, y que es evidente en la escritura y en diseños que se seleccionan para responder a los interrogantes de investigación.

No es tarea fácil para un investigador seleccionar un método a seguir cuando el abanico de posibilidades para responder a una pregunta de investigación es cada vez más amplio. Así, cuando llega a las manos de un lector un documento de investigación, además del contenido conceptual, es muy importante reconocer que fueron necesarias una serie de decisiones para la adopción de una ruta metodológica particular; y que estas decisiones implicaron ganancias y renuncias que hacen parte del ciclo científico, en la medida en que desde las ganancias surgen claridades que permiten avances, pero desde las renuncias surgen también posibilidades de nuevos caminos no explorados, que pueden ser transitados por otros investigadores.

Ahora bien, contar con información de calidad y una adecuada estructura metodológica requiere el soporte de una configuración visual que corresponda a la proyección de la revista. En este sentido, la diagramación de la Revista Colombiana de Rehabilitación hoy tiene un sello distintivo desde su composición de imágenes, colores y forma; que, así como el contenido conceptual, propone imágenes originales de artistas talentosos que crean las obras a partir de las descripciones de los temas de que trata la revista, así, al leer cada documento, no hay que dudar en observar el contenido de la imagen que lo acompaña. 
Esta atrayente combinación de componentes constitutivos de la Revista Colombiana de Rehabilitación, está nuevamente presente en el volumen 16, que se nutre de productos de investigación en temáticas de interés para los profesionales en rehabilitación. Así, el reconocer la "Acción del fisioterapeuta en situaciones de desacondicionamiento en unidades de cuidado intensivos", aporta herramientas a los profesionales en Fisioterapia para su acción profesional en escenarios en los que cada decisión se puede constituir como determinante de la vida de una persona; $y$ reconoce las restricciones para la movilidad en unidades de cuidado intensivo como determinantes de condiciones de salud que pueden ser revertidos desde la acción profesional oportuna.

Así mismo, la propuesta de "Tratamiento fisioterapéutico para la inhibición muscular artrogénica en la rehabilitación de lesiones articulares", propone una mirada fresca al abordaje de las lesiones articulares, que ciertamente involucra ajustes biomecánicos novedosos dentro de los planes terapéuticos, que pueden ser extrapolados en diferentes contextos de la rehabilitación.

Ahora bien, cuando se presentan eventos poco frecuentes, los estudios de caso pueden aportar miradas terapéuticas valiosas para el abordaje clínico en la medida en que logran profundizar en las realidades de los eventos en salud, reconociendo las diferencias en la manifestación de un evento en salud, que van más allá de las generalizaciones que presentan frecuentemente los textos clínicos. En este sentido, el artículo "Rehabilitación pulmonar post-operatoria en un caso de resección en cuña por carcinoma broncogénico. Estudio de caso", contiene elementos que pueden ser de valiosos para los profesionales que se enfrentan a casos en oncología.

Por otro lado, identificar el "Proceso de bioseguridad en los equipos de aerosolterapia por cuidadores primarios y profesionales en atención domiciliaria", proporciona información necesaria para reducir la probabilidad de riesgos biológicos por contaminación cruzada, que cada vez son más frecuentes cuando el cuidado de una personas con un evento de origen respiratorio sale de las instituciones hospitalarias, y se lleva a la cotidianidad del hogar, en donde los cuidados a los equipos puede pasar inadvertido por los involucrados en su manejo.

Como cierre documental, reconocer la "Relación entre características resilientes y riesgo psicosocial en personas con discapacidad" amplía la mirada no sólo del profesional en psicología, sino de los diferentes involucrados en el abordaje de personas con discapacidad, en la medida en que propone reconocer la capacidad de recuperarse luego de una situación adversa como predictivo del riesgo psicosocial como variable de análisis. Esto puede determinar la toma de decisión del profesional en cuanto al abordaje del riesgo en contextos de inclusión laboral, sólo conociendo las características de resiliencia de la persona.

Finalmente, la Revista Colombiana de Rehabilitación agradece a los artistas que participaron en esta publicación, quienes logran con cada línea y color seleccionado, contar una historia que complementa los artículos desde una mirada que no es necesariamente académica o investigativa, y que hace posible reconocer la forma en que nuestras publicaciones son vistas fuera de las comunidades académicas y permite acercarnos cada vez más a lectores que no necesariamente están vinculados al ambiente de producción de conocimiento especializado, abriendo puertas y lazos entre las artes y la ciencia.

Carlos Alberto Pérez Gómez Docente-Investigador 